\title{
Treatment of hypertensive emergencies
}

\author{
Wilbert S. Aronow \\ Cardiology Division, Department of Medicine, Westchester Medical Center and New York Medical College, Valhalla, NY, USA \\ Correspondence to: Wilbert S. Aronow, MD, FACC, FAHA. Professor of Medicine, Cardiology Division, Westchester Medical Center and New York \\ Medical College, Macy Pavilion, Room 141, Valhalla, NY 10595, USA. Email: wsaronow@aol.com.
}

Submitted Feb 10, 2017. Accepted for publication Feb 14, 2017.

doi: 10.21037/atm.2017.03.34

View this article at: http://dx.doi.org/10.21037/atm.2017.03.34

Hypertensive emergencies are diagnosed if there is a systolic blood pressure higher than $180 \mathrm{mmHg}$ or a diastolic blood pressure higher than $120 \mathrm{mmHg}$ with the presence of acute target organ damage (1-6). Hypertensive urgencies are diagnosed if there is a systolic blood pressure higher than $180 \mathrm{mmHg}$ or a diastolic blood pressure higher than $120 \mathrm{mmHg}$ in an otherwise stable person without clinical or laboratory evidence of acute target organ damage (1-6). These persons need intensification of their antihypertensive drug therapy.

Patients with hypertensive emergencies include those who have a dissecting aortic aneurysm, acute pulmonary edema, acute myocardial infarction, unstable angina pectoris, acute renal failure, acute intracranial hemorrhage, acute ischemic stroke, hypertensive encephalopathy, eclampsia or pre-eclampsia, peri-operative hypertension, a pheochromocytoma crisis, and a sympathomimetic hypertensive crisis caused by use of cocaine, amphetamines, phencyclidine, or monoamine oxidase inhibitors or by abrupt cessation of clonidine or other sympatholytic drugs (1-6). These patients need effective and rapid acting medications administered intravenously to lower the elevated blood pressure safely, protect target organ function, ameliorate symptoms, reduce complications, and improve clinical outcomes (1-6). The 1-year mortality incidence of hypertensive emergencies is more than $79 \%$, and the median survival is 10.4 months if these persons are not treated with antihypertensive drug therapy (7).

The drug of choice in treating acute aortic dissection is intravenous esmolol $(1,5)$. The loading dose is $500-1,000 \mathrm{mcg} / \mathrm{kg} / \mathrm{min}$ administered over $1 \mathrm{~min}$ followed by a $50 \mathrm{mcg} / \mathrm{kg} / \mathrm{min}$ infusion rate. The maximum infusion rate is $200 \mathrm{mcg}$. Rapid and immediate reduction of blood pressure within 5 to $10 \mathrm{~min}$ is needed for patients with acute aortic dissection. The target blood pressure goal in these patients is a systolic blood pressure below $120 \mathrm{mmHg}$. If the blood pressure remains elevated after beta blockade, a vasodilator such as intravenous nitroglycerin or nitroprusside may be administered.

The drugs of choice in treating a hypertensive emergency with acute pulmonary edema are intravenous nitroglycerin, clevidipine, or nitroprusside $(1,2,5)$. Beta blockers are contraindicated in the treatment of acute pulmonary edema. Except for acute aortic dissection, the blood pressure in patients with hypertensive emergencies should be lowered within minutes to $1 \mathrm{~h}$ about $20 \%$ to $25 \%$ and then gradually to $160 / 100 \mathrm{mmHg}$ within the next 2 to $6 \mathrm{~h}$, and then cautiously to normal over the next 24 to $48 \mathrm{~h}$ (1). The initial infusion rate of intravenous nitroglycerin is $5 \mathrm{mcg} / \mathrm{min}$. The maximum infusion rate is $20 \mathrm{mcg} / \mathrm{min}$. The initial infusion rate of intravenous sodium nitroprusside is 0.3 to $0.5 \mathrm{mcg} / \mathrm{kg} / \mathrm{min}$. The maximum infusion rate is $10 \mathrm{mcg} / \mathrm{kg} / \mathrm{min}$. The initial infusion rate of intravenous clevidipine is $1-2 \mathrm{mg} / \mathrm{h}$. The maximum infusion rate is $32 \mathrm{mg} / \mathrm{h}$.

Patients with an acute myocardial infarction or unstable angina pectoris and severe hypertension should be treated with intravenous esmolol (8). Intravenous nitroglycerin may also be administered if needed (8). The target blood pressure is less than $140 / 90 \mathrm{mmHg}$ in patients with acute myocardial infarction or unstable angina pectoris who are hemodynamically stable (8). A blood pressure of less than 130/80 $\mathrm{mmHg}$ at hospital discharge should be considered (8). Caution should be used in lowering the blood pressure in these patients to avoid lowering the diastolic blood pressure to less than $60 \mathrm{mmHg}$ as this may decrease coronary perfusion and aggravate myocardial ischemia (8). 
The drugs of choice in treating patients with a hypertensive emergency and acute renal failure are clevidipine, fenoldopam, and nicardipine (5). The initial infusion rate of intravenous fenoldopam is 0.1 to $0.3 \mathrm{mcg} / \mathrm{kg} / \mathrm{min}$. The maximum infusion rate is $1.6 \mathrm{mcg} / \mathrm{kg} / \mathrm{min}$. The initial infusion rate of intravenous nicardipine is $5 \mathrm{mg} / \mathrm{h}$. The maximum infusion rate is $30 \mathrm{mg} / \mathrm{h}$. In 104 patients with a hypertensive emergency with renal dysfunction treated in an emergency department with intravenous nicardipine or labetalol, within 30 min of administration, the target systolic blood pressure was reached in $92 \%$ of patients treated with intravenous nicardipine versus $78 \%$ of patients treated with intravenous labetalol (9).

The drugs of choice in treating patients with a hypertensive crisis and eclampsia or pre-eclampsia are hydralazine, labetalol, and nicardipine $(5,6)$. Angiotensin-converting enzyme inhibitors, angiotensin receptor blockers, direct renin inhibitors, and sodium nitroprusside are contraindicated in treating these patients. The maximum initial dose of intravenous hydralazine administered by slow intravenous infusion is $20 \mathrm{mg}$. This dose may be repeated every $4-6 \mathrm{~h}$ if needed. The initial dose of intravenous labetalol is 0.3 to $1.0 \mathrm{mg} / \mathrm{kg}$ with a maximum initial dose of $20 \mathrm{mg}$ followed by an intravenous infusion of 0.4 to $1.0 \mathrm{mg} / \mathrm{kg} / \mathrm{h}$ up to $3 \mathrm{mg} / \mathrm{kg} / \mathrm{h}$. The total cumulative dose is $300 \mathrm{mg}$. This dose can be repeated every 4 to $6 \mathrm{~h}$ if needed.

Drugs of choice used for treating postoperative surgical hypertension include administration of intravenous clevidipine, esmolol, nitroglycerin, and nicardipine $(10,11)$. A systematic review and meta-analysis reported that clevidipine was the drug of choice for treating acute postoperative hypertension (10).

Drugs of choice for treating a hypertensive emergency caused by a pheochromocytoma or by an hyperadrenergic state caused by use of cocaine, amphetamines, phencyclidine, or monoamine oxidase inhibitors or by abrupt cessation of clonidine or other sympatholytic drugs are intravenous clevidipine, nicardipine, or phentolamine (1). The initial dose of phentolamine is an intravenous bolus dose of $5 \mathrm{mg}$. Additional bolus doses of $5 \mathrm{mg}$ should be administered intravenously every $10 \mathrm{~min}$ as needed to reduce the blood pressure to the target level.

Intravenous enalaprilat may be administered to patients with a hypertensive emergency associated with a high plasma renin state $(5,6,12)$. The initial dose of enaliprilat administered intravenously is $1.25 \mathrm{mg}$ over $5 \mathrm{~min}$. Additional doses of intravenous enaliprilat may be given up to $5 \mathrm{mg}$ every $6 \mathrm{~h}$ as needed to reach the blood pressure target level.

A study randomized 104 patients with acute heart failure with hypertension to receive intravenous clevidipine versus standard of care intravenous antihypertensive drugs (87\% intravenous nitroglycerin or nicardipine) (13). This study showed that the target blood pressure level was reached in $71 \%$ of patients treated with clevidipine versus $37 \%$ of those receiving standard of care intravenous antihypertensive drugs. Clevidipine was also more effective than standard of care drugs in improving dyspnea at $45 \mathrm{~min}$ (13).

A study randomized 226 patients in an emergency department with a hypertensive emergency to treatment with intravenous nicardipine versus intravenous labetalol (14). Within $30 \mathrm{~min}$, the target blood pressure level was reached in $91.7 \%$ of patients treated with intravenous nicardipine versus $82.5 \%$ of patients treated with intravenous labetalol (14). A subgroup of this study included 141 patients with signs and/or symptoms of target organ damage (15). Within $30 \mathrm{~min}, 91.4 \%$ of these patients randomized to intravenous nicardipine reached their target blood pressure level versus $76.1 \%$ of these patients randomized to intravenous labetalol (15).

A Cochrane systematic review of pharmacological interventions for hypertensive emergencies included 15 randomized controlled trials of 869 patients treated with seven drug classes (4). There were insufficient data to determine which antihypertensive drug is most effective in decreasing mortality and morbidity (4). Randomized clinical trials are needed to investigate initial and longterm mortality outcomes in patients with hypertensive emergencies treated with different antihypertensive drugs. Randomized clinical trial data are also needed to determine how fast or how much the blood pressure should be lowered in a hypertensive emergency.

A study randomized 2,794 patients with a hypertensive emergency and acute intracerebral hemorrhage to a target blood pressure level of less than $140 \mathrm{mmHg}$ within $1 \mathrm{~h}$ or to less than $180 \mathrm{mmHg}$ within $1 \mathrm{~h}$ using intravenous antihypertensive drugs chosen by the different physicians (16). The reduction of the systolic blood pressure to less than $140 \mathrm{mmHg}$ was associated with a $13 \%$ borderline reduction in the primary outcome of death or major disability but with improved functional outcomes compared with reduction of the systolic blood pressure to less than $180 \mathrm{mmHg}$ within $1 \mathrm{~h}$ (16). A meta-analysis of four randomized clinical trials including 3,315 patients with a hypertensive emergency and acute intracerebral hemorrhage demonstrated that intensive blood pressure lowering in these 
patients to less than $140 \mathrm{mmHg}$ was associated with a $13 \%$ borderline reduction in 3-month death or dependency (17). Intensive blood pressure lowering in acute cerebral hemorrhage also seems to reduce hematoma growth (18).

The antihypertensive drug of choice for treating acute cerebral hemorrhage needs to be investigated by randomized clinical trials. Rapid acting, easily titratable drugs administered intravenously such as clevidipine, nicardipine, labetalol, and urapidil are reasonable first-line drugs for treating these patients (3).

The 2013 American Heart Association/American Stroke Association acute ischemic stroke guidelines state that it is unknown what the blood pressure target level should be for patients with acute ischemic stroke or which antihypertensive drug should be recommended (19). These guidelines currently recommend not reducing the blood pressure during the initial $24 \mathrm{~h}$ of acute ischemic stroke unless the blood pressure is above $220 / 120 \mathrm{mmHg}$ or there is a specific medical disorder that would benefit from blood pressure reduction. In patients with acute ischemic stroke eligible for acute reperfusion therapy, these guidelines recommend lowering the blood pressure to below 180/110 mmHg before administering fibrinolytic therapy with intravenous labetalol or with intravenous nicardipine with consideration of other intravenous antihypertensive drugs when appropriate (19).

\section{Acknowledgements}

None.

\section{Footnote}

Conflicts of Interest: The author has no conflicts of interest to declare.

\section{References}

1. Papadopoulos DP, Sanidas EA, Viniou NA, et al. Cardiovascular hypertensive emergencies. Curr Hypertens Rep 2015;17:5.

2. Peacock F, Amin A, Granger CB, et al. Hypertensive heart failure: patient characteristics, treatment, and outcomes. Am J Emerg Med 2011;29:855-62.

3. Manning L, Robinson TG, Anderson CS. Control of blood pressure in hypertensive neurological emergencies. Curr Hypertens Rep 2014;16:436.

4. Perez MI, Musini VM. Pharmacological interventions for hypertensive emergencies: a Cochrane systematic review. J Hum Hypertens 2008;22:596-607.

5. Rhoney D, Peacock WF. Intravenous therapy for hypertensive emergencies, part 1. Health Syst Pharm 2009;66:1687.

6. Rhoney D, Peacock WF. Intravenous therapy for hypertensive emergencies, part 2. Am J Health Syst Pharm 2009;66:1448-57.

7. Keith NM, Wagener HP, Barker NW. Some different types of essential hypertension: their course and prognosis. Am J Med Sci 1974;268:336-45.

8. Rosendorff C, Lackland DT, Allison M, et al. Treatment of Hypertension in Patients With Coronary Artery Disease: A Scientific Statement from the American Heart Association, American College of Cardiology, and American Society of Hypertension. J Am Coll Cardiol 2015;65:1998-2038.

9. Varon J, Soto-Ruiz KM, Baumann BM, et al. The management of acute hypertension in patients with renal dysfunction: labetalol or nicardipine? Postgrad Med 2014;126:124-30.

10. Espinosa A, Ripollés-Melchor J, Casans-Francés R, et al. Perioperative Use of Clevidipine: A Systematic Review and Meta-Analysis. PLoS One 2016;11:e0150625.

11. Aronson S, Dyke CM, Stierer KA, et al. The ECLIPSE trials: comparative studies of clevidipine to nitroglycerin, sodium nitroprusside, and nicardipine for acute hypertension treatment in cardiac surgery patients. Anesth Analg 2008;107:1110-21.

12. Ayaz SI, Sharkey CM, Kwiatkowski GM, et al. Intravenous enalaprilat for treatment of acute hypertensive heart failure in the emergency department. Int J Emerg Med 2016;9:28.

13. Peacock WF, Chandra A, Char D, et al. Clevidipine in acute heart failure: Results of the A Study of Blood Pressure Control in Acute Heart Failure-A Pilot Study (PRONTO). Am Heart J 2014;167:529-36.

14. Peacock WF, Varon J, Baumann BM, et al. CLUE: a randomized comparative effectiveness trial of IV nicardipine versus labetalol use in the emergency department. Crit Care 2011;15:R157.

15. Cannon CM, Levy P, Baumann BM, et al. Intravenous nicardipine and labetalol use in hypertensive patients with signs or symptoms suggestive of end-organ damage in the emergency department: a subgroup analysis of the CLUE trial. BMJ Open 2013;3.

16. Anderson CS, Heeley E, Huang Y, et al. Rapid bloodpressure lowering in patients with acute intracerebral hemorrhage. N Engl J Med 2013;368:2355-65. 
17. Tsivgoulis G, Katsanos AH, Butcher KS, et al. Intensive blood pressure reduction in acute intracerebral hemorrhage: a meta-analysis. Neurology 2014;83:1523-9.

18. Anderson CS, Huang Y, Wang JG, et al. Intensive blood pressure reduction in acute cerebral haemorrhage trial (INTERACT): a randomised pilot trial. Lancet Neurol
2008;7:391-9.

19. Jauch EC, Saver JL, Adams HP Jr, et al. Guidelines for the early management of patients with acute ischemic stroke: a guideline for healthcare professionals from the American Heart Association/American Stroke Association. Stroke 2013;44:870-947.
Cite this article as: Aronow WS. Treatment of hypertensive emergencies. Ann Transl Med 2017;5(Suppl 1):S5. doi: 10.21037/atm.2017.03.34 